
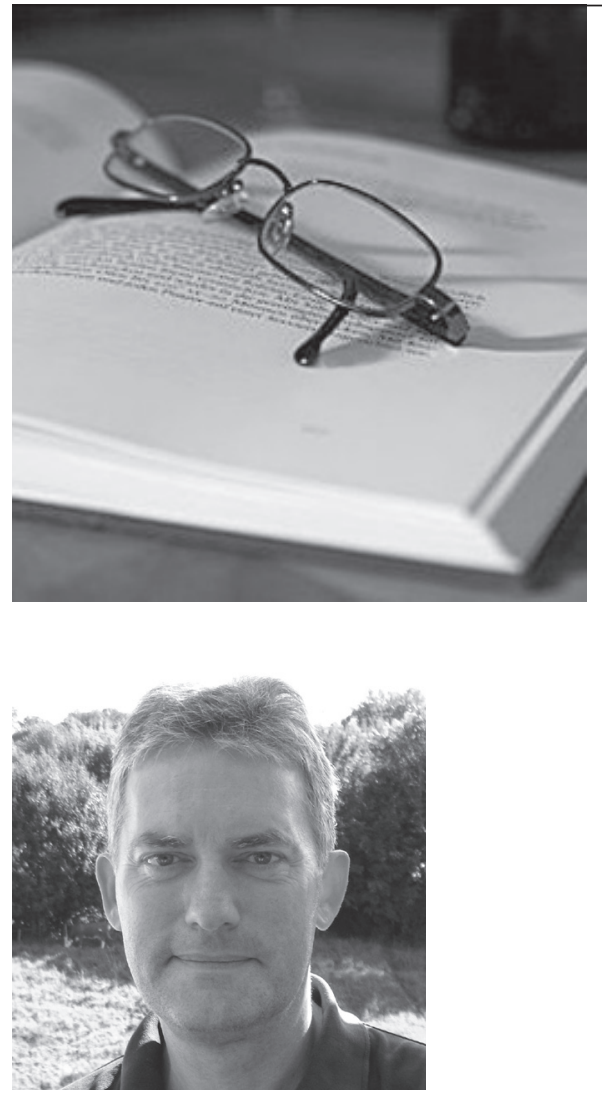

VON WOLFGANG TREDE

Der Diplom-Pädagoge Wolfgang

Trede ist seit zehn Jahren Leiter

des Amtes für Jugend und Bildung

des Landkreises Böblingen. Zuvor

war er Geschäftsführer des Insti-

tuts für Erziehungswissenschaft

der Universität Tübingen und

Geschäftsführer der Internationa-

len Gesellschaft für erzieherische

Hilfen (IGfH) in Frankfurt am

Main. Derzeit ist er Mitglied der

Sachverständigenkommission für

den 14. Kinder- und Jugendbericht

der Bundesregierung.

E-Mail w.trede@|rabb.de

\title{
Kompass für Fachlichkeit und Führung
}

SOZIALwirtschaft fragt regelmäßig Experten der Branche, welches Buch sie in ihrer Arbeit am meisten beeinflusst hat.

Bis heute gilt der Achte Jugendbericht von 1990 als Meilenstein der fachlichkonzeptionellen Entwicklung der deutschen Kinder- und Jugendhilfe. Sein Konzept einer lebensweltorientierten Jugendhilfe und die damit verbundenen "Strukturmaximen " Prävention, Dezentralisierung/Regionalisierung, Alltagsorientierung, Integration, Normalisierung und Partizipation sind $\mathrm{zu}$ Leitbegriffen moderner sozialer Arbeit geworden und können auch in den Zehner Jahren des 21. Jahrhunderts - unter völlig gewandelten gesellschaftlichen Verhältnissen - noch viel Anregungsfunktion entfalten, wenn auch teilweise mit neuen Begrifflichkeiten (vgl. z. B. Debatte um Inklusion). Führender Kopf der damaligen Autorengruppe des Jugendberichts war der Tübinger Sozialpädagogik-Professor Hans Thiersch.

Thiersch war auch einer der mich persönlich besonders prägenden Hochschullehrer während meines Studiums der Erziehungswissenschaft und mein erster Chef gewesen, als ich in den 1980er Jahren Geschäftsführer des erziehungswissenschaftlichen Instituts der Universität Tübingen war. Ich kann mich noch gut erinnern, wie Thiersch als Mitglied der damaligen Sachverständigenkommission des 8. Jugendberichts Ende der 19890er Jahre in vielen abendlichen Runden einzelne Berichtsentwürfe vorstellte, zu kritischer Diskussion einlud und unser Feedback einforderte.

Hans Thiersch hat mit seinem konzeptionellen Wurf einer Sozialen Arbeit, die sich auf den Alltag hilfebedürftiger und benachteiligter Menschen in all seiner Widersprüchlichkeit zu beziehen habe und sich in ihrem Handeln an deren Lebenswelt - kritisch aber mit Respekt und pädagogischem Takt - zu orientieren habe, einer ganzen Generation von Sozialarbeitern und Sozialpädagogen einen fachlichen Kompass zur Verfügung gestellt.

In seinem 1992 erstmals erschienen Buch »Lebensweltorientierte Soziale Arbeit « finden sich die Anliegen des 8. Jugendberichts und Thierschs Ansatz einer lebenswelt- und alltagsorientierten Pädagogik konzentriert aufbereitet. Der Band hat mich über viele Berufsjahre fachlich, interessanterweise aber gerade auch im Bereich des eigenen Führungsverhaltens immer wieder inspiriert. Denn die lebensweltorientierte soziale Arbeit gibt - zumindest für einen dialogorientierten Führungsstil - ebenfalls einen guten Kompass ab.

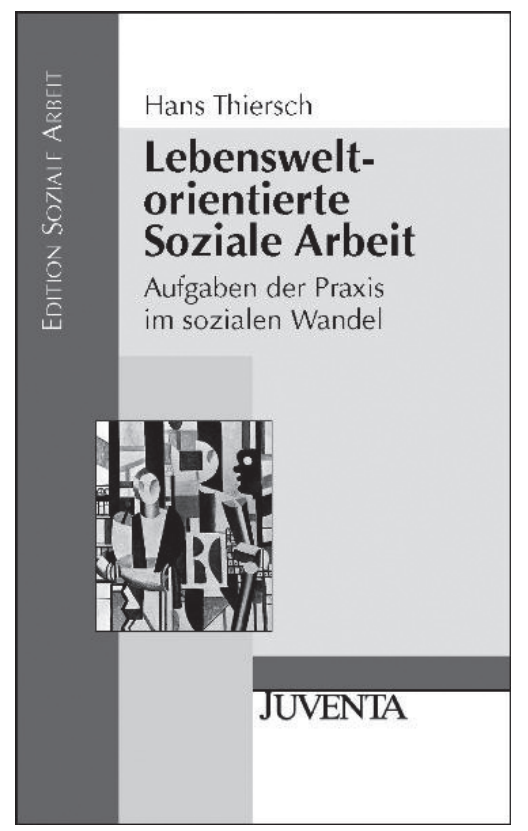

Hans Thiersch: Lebensweltorientierte Soziale Arbeit. Juventa, Weinheim und München 1992. ISBN 3-7799-1002-0. (Derzeit im Buchhandel erhältlich ist die 7. Auflage von 2008 für 16,95 Euro.) 